\title{
Fascial distorsion techniques according to Typaldos for patients with chronic musculoskeletal and postsurgical
}

pain-syndrome

Friederike Jandl, MD; Anna Krug, MD; Ingrid Riener, MD; Tatjana Paternostro-Sluga, MD PhD

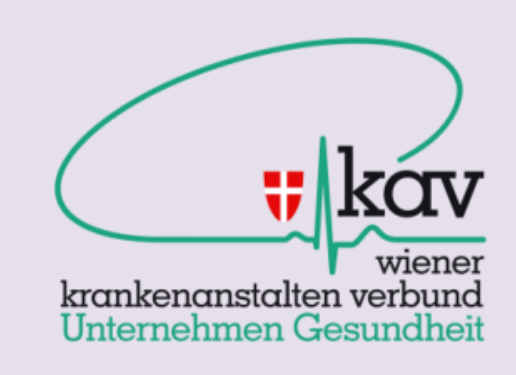

Department of Physical Medicine and Rehabilitation, Danube Hospital, Vienna Hospital

Association, Langobardenstr. 122, 1220 Vienna

\section{Objective:}

The aim of the study was to examine the treatment effect of fascial distortion techniques according to Typaldos in patients with chronic musculoskeletal pain syndromes as well as patients after after surgery to relief pain.

Design: retrospective, descriptive

\section{Material and Methods:}

13 patients ( 2 men, 11 women, $\bar{x}=48.7$ y) with chronic musculoskeletal pain syndromes (> 3 months) and patients after orthopedic surgery were included.

The painful area of the body was treated treated with fascial distortion techniques according to Typaldos.

2 treatment sessions were performed within an average interval of 2 weeks.

\section{Outcome measurement:}

Pain intensity according to the visual analog scale (VAS o-10) was assessed before start of treatments as well as on average 10 to 14 days after the $1^{\text {st }}$ and $2^{\text {nd }}$ treatment.

\section{Contact information:}

friederike.jandl@wienkav.at, tatjana.paternostro-sluga@wienkav.at

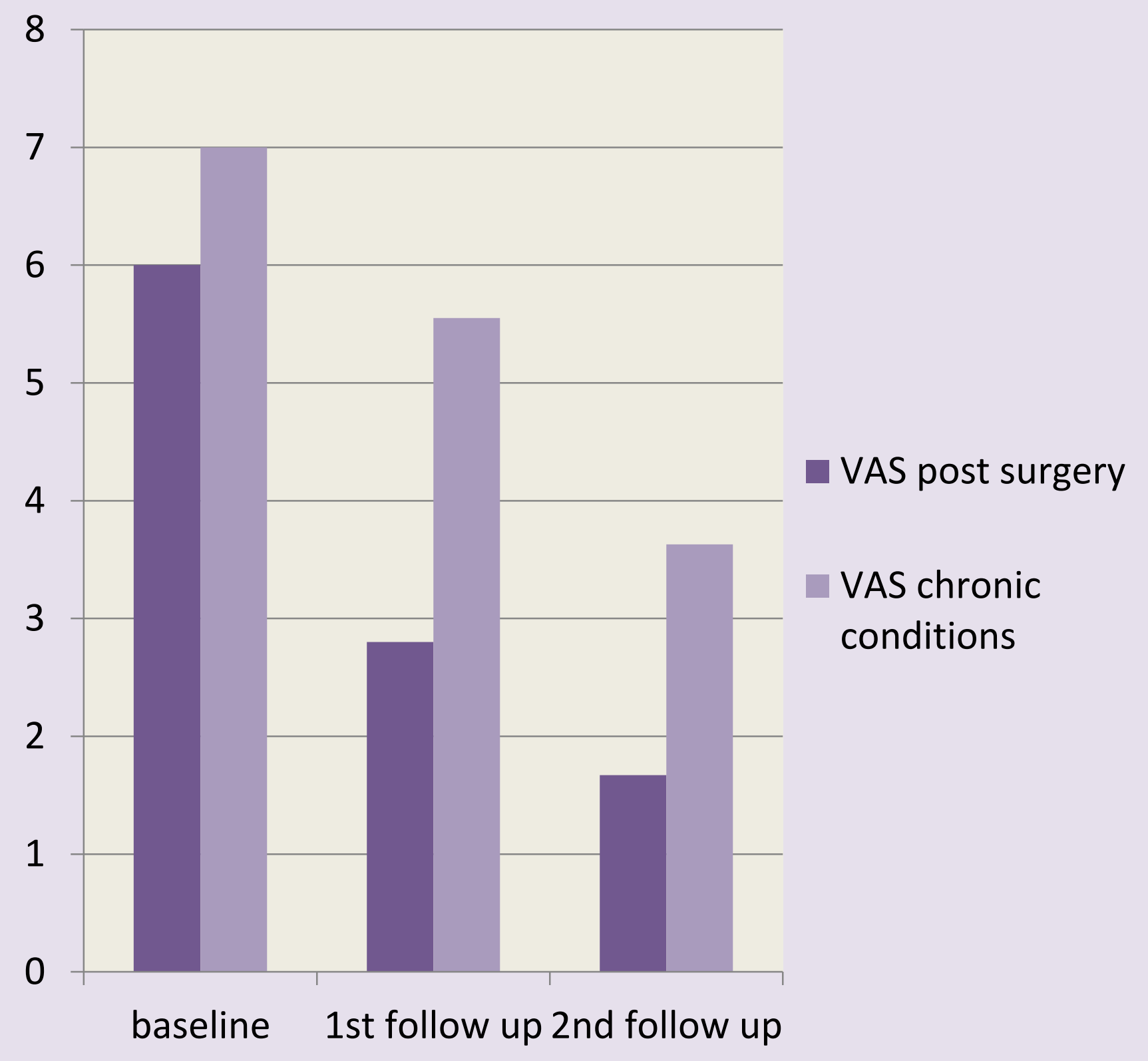

\section{Results:}

All patients showed improvement. The average improvement for patients with chronic pain syndromes between baseline and $1^{\text {st }}$ follow up was $20.8 \%$, between baseline and $2^{\text {nd }}$ follow up $48.2 \%$. The average improvement for patients after surgery between baseline and $1^{\text {st }}$ follow up was $53.3 \%$, between baseline and $2^{\text {nd }}$ follow up $72.2 \%$.

\section{Conclusion:}

Fascial distorsion techniques could improve pain intensity in chronic as well as postsurgical musculoskeletal conditions. 